\title{
Gênero, medicina e filantropia: Maria Rennotte e as mulheres na construção da nação*
}

\begin{abstract}
Maria Lucia Mott**
Resumo

O artigo analisa a trajetória da belga Maria Rennotte que em 1878 mudou-se para o Brasil, onde trabalhou como preceptora, professora e médica. Com seus escritos e sua prática social, Maria Rennotte lutou pelos direitos das mulheres a uma melhor educação, ao acesso a diferentes tipos de trabalho, à obtenção de um corpo mais saudável, à cidadania política. Pregou a participação das mulheres em entidades assistenciais, e fundou uma filial da Cruz Vermelha na capital paulista. A análise de sua trajetória possibilita afirmar que apesar de desconsideradas politicamente, não terem reconhecidos os direitos civis, possuírem limitadas oportunidades educacionais e de trabalho remunerado e serem identificadas basicamente como mães e esposas, pela atuação nas associações filantrópicas as mulheres participaram efetivamente da vida nacional, deixando sua marca nos serviços prestados à população, nas leis, na organização de instituições de ensino e de saúde e no desenvolvimento do conhecimento científico.
\end{abstract}

Palavras-Chave: Filantropia, Gênero, Profissionais de Saúde, Medicina, Cruz Vermelha, Maria Rennotte

\footnotetext{
* Recebido para publicação em janeiro de 2005, aprovado em fevereiro de 2005.

*** Instituto de Saúde-SESSP, São Paulo, SP, Brasil. cucamott@uol.com.br
} 
Gênero, medicina e filantropia

Gender, Medicine and Philanthropy:

Maria Renotte and Women in the Building of the Nation

\begin{abstract}
The article analyses the trajectory of Maria Rennotte, a Belgian who in 1878 moved to Brazil working as a governess, and afterwards as a teacher and doctor. With her writings and social practice, Maria Rennotte fought for women's rights in search for better education, access to different types of work, a healthier body and political citizenship. She asserted women's participation in assistance entities, founding a Red Cross branch in São Paulo. Her trajectory enables us to state that although women were not politically considered in terms of their civil rights, had limited educational opportunities and few chances of wage-earning jobs, basically being identified as mothers and wives, they found in philanthropic associations a breach to enlarge their participation in the public sphere. Acting in national life, women changed the services offered to the people, the law, the educational and health institutions and the development of scientific knowledge.
\end{abstract}

Key-words: Philanthropy, Gender, Health Professionals, Medicine, Red Cross, Maria Renotte 
A luta contra a pobreza, a miséria moral e intelectual, a doença, a morte é uma questão recorrente na história da humanidade, mas a forma de enfrentamento tem variado ao longo do tempo, diz Evelyne Diebolt. A historiadora observa que, na França no final do século XIX e início do XX, parte da sociedade civil se organizou em associações para remediar esses problemas e obter junto ao poder público e a sociedade civil financiamento para a ação social concreta, bem como leis sociais. Salienta que as mulheres tiveram um papel fundamental na criação, organização e gestão dessas associações. ${ }^{1}$

No Brasil, a história das associações filantrópicas, também criadas a partir do final do século XIX, é pouco conhecida, excetuando-se talvez as patrocinadas pelas Santas Casas, o Instituto de Assistência e Proteção à Infância, criado pelo médico Moncorvo Filho, no Rio de Janeiro, e a Fundação Ataulpho de Paiva. ${ }^{2}$ Permanece na historiografia a imagem da filantropia como obra masculina, sendo as mulheres vistas como coadjuvantes, meras organizadoras de festas para levantamento de fundos, bem como é pouco conhecido o papel que elas tiveram na criação, manutenção e elaboração dos programas de associações de assistência educacional, médica e social.

Este artigo tem por objetivo trazer subsídios para a análise da participação das mulheres nas associações médico-sociais no Brasil, na passagem do século XIX para o XX. Destaca o papel que estas entidades tiveram na profissionalização e na luta por

1 Paris, Femmes et Associations, 2002. Sobre gênero e filantropia ver também McCARTHY, K.D. Women and Political Culture. In: FriedmAN, Lawrence J. \& McGarvie, Mark. D. (ed.) Charity, Philanthropy and Civility in American History. New York, Cambridge University Press, 2003, pp.179-198.

2 Rizzini, Irene. O século perdido. Raízes Históricas das Políticas Públicas para a Infância no Brasil. Rio de Janeiro, Petrobrás/Ministério da Cultura/Universidade Santa Úrsula, 1997; WADSWORTH, J. E. Moncorvo Filho e o problema da infância: modelos institucionais e ideológicos da assistência à infância no Brasil. Revista de História, vol.19, $\mathrm{n}^{\circ}$ 37, 1999, pp.103-124; NASCIMENTO, D.N. Fundação Ataulpho de Paiva. Liga Brasileira contra a tuberculose. Um século de luta. Rio de Janeiro, Faperj/Quadratin, 2004. 
Gênero, medicina e filantropia

melhores condições de vida das mulheres e na prestação de assistência médica para a população mais pobre. Baseia-se nos escritos e na ação de Maria Rennotte, senão a primeira, uma das primeiras médicas a exercer a profissão na cidade de São Paulo.

\section{Educadora e médica}

Na biografia de Maria Rennotte (1842-1952) dois tipos de comportamento chamam a atenção: a mobilidade espacial, traduzida por inúmeras viagens de estudo, trabalho e lazer, e a capacidade ou o desejo de intervir na realidade social, seja expressando publicamente suas opiniões, algumas vezes de forma polêmica, sobre assuntos diversos como educação, saúde, função social e direitos das mulheres, seja atuando em diferentes projetos voltados para a assistência médica e social. $\mathrm{O}$ crescente número de pesquisas realizadas nas últimas décadas possibilita afirmar que tais atitudes eram menos raras e excepcionais na virada do século XIX e início do século XX do que se acreditava até bem recentemente, apesar do valor social atribuído à vida doméstica $e$ familiar para o sexo feminino, e das inúmeras estratégias de cerceamento utilizadas para restringir a atuação pública das mulheres.

Nascida na Bélgica, Maria Rennotte fez o curso para magistério em Paris, e foi professora na Alemanha onde ensinou francês. Sobre os motivos que a teriam trazido, em 1878, ao Brasil, como preceptora, não se sabe. A documentação informa que exerceu a profissão apenas por algum tempo, o que sugere que tenha sido a maneira de se estabelecer e ser conhecida no país, um caminho para novos projetos profissionais. ${ }^{3}$

$\mathrm{O}$ fato de ter diploma do magistério certamente possibilitou que cerca de quatro anos depois ela fosse contratada pelo Colégio

3 Carta de apresentação feita por Ribeiro Avellar? (assinatura ilegível), 6/5/1881. Fundo Maria Rennotte, Instituto Histórico Geográfico de São Paulo. 
Piracicabano, na cidade de Piracicaba (interior de São Paulo). ${ }^{4} \mathrm{O}$ colégio foi fundado em 1881, por metodistas do Sul dos Estados Unidos com a ajuda de políticos do partido republicano e era conhecido pelas idéias inovadoras sobre educação das mulheres. ${ }^{5}$ Maria Rennotte fugia do perfil mais conhecido de preceptora $e$ professora de escolas femininas, cujo ensino era voltado para o francês, para as prendas domésticas e artes de salão. ${ }^{6}$

A professora era defensora da igualdade entre os sexos, coeducação, métodos de ensino criativos que desenvolvessem o

4 Agradeço a Zuleica Mesquita pelo acesso aos documentos do Arquivo da UNIMEP, a Márcia Oehlmeyer Costa, pelas referências da Gazeta de Piracicaba e do Expositor Cristão, a Laura Berchansky pela pesquisa do Expositor Cristão e a Olga Sofia F. Alves pela leitura da primeira versão do texto.

${ }^{5}$ BARBANTI, M.L.S.H. Escolas americanas de confissão protestante na Província de São Paulo: um estudo de suas origens. Dissertação de Mestrado, Faculdade de Educação, USP, 1977; EliAS, B. V. Vieram e Ensinaram: Colégio Piracicabano, 120 anos. Piracicaba-SP, Editora UNIMEP, 2001.

6 A preceptoria foi uma forma de educação doméstica utilizada pelas camadas médias e de elite especialmente no século XIX. Era um tipo de trabalho remunerado socialmente aceito para o sexo feminino. A bibliografia nacional $e$ estrangeira descreve as preceptoras como sendo mulheres solteiras, provenientes de famílias empobrecidas, cujo status era considerado, com raras exceções, próximo dos empregados domésticos. A imigração seria uma forma de esconder de familiares e conhecidos o exercício do ofício. Apesar do poder que muitas adquiriram junto às famílias que trabalhavam, as preceptoras são lembradas principalmente como mulheres de um rigor disciplinar em relação aos educandos, próximo à crueldade, de moral duvidosa (veja-se a Fraulien, em Amar, Verbo Intransitivo de Mário de Andrade) e interesseiras. Poucas vezes são mencionados exemplos positivos, como o de Maria Rennotte (e da física Marie Curie, que foi preceptora para que a irmã pudesse fazer curso de medicina em Paris). Nesse sentido o estudo da trajetória de vida da médica belga adquire uma dimensão maior pois possibilita redimensionar o perfil das preceptoras, bem como a formação das moças feitas no âmbito doméstico, no Brasil. Sobre preceptoras ver: MENDONÇA, Ana V. A casa e seus mestres: a educação doméstica como uma prática das elites no Brasil no oitocentos. Tese de doutorado, PUCRJ, 2004; RITZKAT, M.G.B. Preceptoras Alemãs no Brasil. In: LOPES, E.M.T. et alii. 500 anos de educação no Brasil. Belo Horizonte, Autêntica, 2000; MonTEIRO, C. Corpos des(autorizados). A preceptora na ficção inglesa e brasileira. Estudos Anglo-Americanos, vol.25, n 25, 2001/2002, pp.69-79. 
Gênero, medicina e filantropia

raciocínio, inclusão de disciplinas voltadas para as ciências naturais e biológicas no currículo das escolas femininas. Deu aulas de francês, matemática e ciências regularmente no Colégio, abriu classes mistas noturnas de química e física, fez palestras, criou um museu de história natural e uma sociedade literária, comemorou com suas alunas festas cívicas, nas quais cantavam versos da Marsellaise em pleno regime escravista e monárquico, e criticou o catolicismo que impregnava todos aspectos da vida nacional. Publicou, nesse período, muitos textos num tom que hoje diríamos panfletário nos jornais Gazeta de Piracicaba, A Província de São Paulo, O Estado de São Paulo, Diário Popular, Correio Paulistano, Município, A Mensageira e A Família, um dos principais periódicos feministas de então. Entre 1886/7, viajou para os Estados Unidos com o objetivo de estudar novos métodos de ensino, de onde mandou pelo menos um artigo sobre educação para o jornal $A$ Província de São Paulo de 7/11/1886, e à França, de onde trouxe material didático para suas aulas de ciências. ${ }^{7}$

Como já assinalei em outro artigo, em 1889, a trajetória profissional da professora tomou outro rumo. Depois de visitar a Exposição Universal em Paris, com quase 40 anos, mudou-se para a Filadélfia, nos Estados Unidos, obtendo três anos depois o diploma de médica no Woman's Medical College of Pennsylvania (WMCP). Primeira de uma série de escolas de medicina norteamericanas exclusivas para mulheres, a WMCP foi fundada nos anos 1850 pela comunidade Quaker da Filadélfia (EUA), onde se formaram algumas das mais conhecidas e conceituadas médicas norte-americanas. ${ }^{8}$

No Brasil, vale destacar, os locais para ensino médico eram restritos. Até 1897, existiam apenas duas faculdades de medicina,

7 CAmbiaghi, O. Medicina em Piracicaba. Piracicaba-SP, Degaspari, 1984.

8 O estado da Pennsilvania possuía uma comunidade quaker reformista bastante atuante, era considerado um centro médico importante, onde foram criadas sete escolas médicas entre 1840 e 1850. Sobre o WMCP ver: ALSOP, G.F. History of the Woman's Medical College of Pennsylvania (1850-1950). Philadelphia, J.B. Lippincott Company, 1950. 
a do Rio de Janeiro e a da Bahia, que vinham aceitando matrículas de mulheres há pelo menos uma década, desde a reforma Leôncio de Carvalho, porém com uma freqüência reduzida. ${ }^{9}$ Mesmo São Paulo, apesar da dianteira em políticas de saúde pública, viu inaugurada somente em 1913 uma faculdade de medicina oficialmente reconhecida.

A possibilidade de Mlle Rennotte freqüentar o curso no exterior deveu-se ao então presidente de província de São Paulo, Prudente de Moraes Barros, defensor do ensino ministrado pelos protestantes. ${ }^{10} \mathrm{~A}$ idade certamente não foi empecilho, visto na época o ingresso por muitas mulheres, em diferentes profissões, ocorrer mais tarde, quando já tinham obtido recursos em outras atividades e não precisavam mais responder à autoridade paterna. $^{11}$

A documentação levantada não forneceu nenhuma pista, infelizmente, quanto à razão da escolha do WMCP. Porém, nos Estados Unidos, o acesso das mulheres aos cursos de medicina já tinha uma tradição de mais de 30 anos. Se até o final do século o número de médicas formadas no Brasil não chegava a uma dezena, nos Estados Unidos havia mais de cinco mil clinicando e apenas no ano de 1898, tinham sido matriculadas 377 alunas. ${ }^{12}$

\footnotetext{
9 Sobre mulheres e ensino médico no Brasil ver: MoTT, M.L. De educadora a médica..., Op. cit.; RAGO, E.J. A ruptura do mundo masculino da medicina: médicas brasileiras no século XIX. Cadernos Pagu (15), Núcleo de Estudos de Gênero-Pagu/Unicamp, 2000, pp.199-225 e Medicina e feminismo no século XX. Francisca Praguer Fróes (Bahia, 1872-1931). Revista do Instituto Histórico Geográfico Brasileiro, vol.163, n 415, abr/jun, 2002, pp.53-66.

${ }^{10}$ CAmbiaghi, O. Medicina em Piracicaba..., Op. cit.

${ }^{11}$ MotT, M. L. De educadora a médica..., Op. cit.

${ }^{12}$ WeLls, Susan. Out of the House. Nineteenth-Century Women and the Writing of Medicine. Wisconsin, Wisconsin University Press, 2001. Sobre mulheres médicas nos Estados Unidos ver SANCHEZ, R. M. The Gendering of Emphatic Expertise: How Woman Became more Emphatic than Man. In: LEAVITT, J.W. Women and Health in America. Madison, The University of Wisconsin Press, 1999; SANCHEZ, R. M. The "Connecting Link": The Case for the Woman Doctor in 19th Century America. In: LEAVITT, J.W. e NumBERS, R. Sickness and Health in
} 
Gênero, medicina e filantropia

O WMCP tinha por objetivo instruir mulheres nos vários campos da medicina, num curso de qualidade que em nada ficasse a dever aos ministrados pelas escolas norte-americanas $e$ européias oficiais. Possuía idéias avançadas para a época sobre educação e profissionalização das mulheres, condenava o uso do espartilho, defendia aulas de anatomia, fisiologia e educação física, o acesso do sexo feminino às profissões rentáveis e a importância de se educar e formar enfermeiras - idéias, aliás, também defendidas pela nossa biografada. ${ }^{13}$

Depois de se formar em 1893, Maria Rennotte fez curso complementar nos hospitais de Paris, como era recomendado para profissionais que quisessem ter uma melhor formação clínica. ${ }^{14}$ De volta ao Brasil, se estabeleceu em São Paulo como médica, onde já tinha relação com um núcleo diferenciado de pessoas. A capital do estado, na época, começava a escalada de crescimento econômico e populacional, abrigando uma elite educada, nacional e estrangeira, favorável à expansão dos serviços de saúde pública e privada. Tinham sido criadas instituições públicas de combate às epidemias de reconhecida eficiência e prestígio; inaugurados hospitais privados; fundada uma maternidade.

Maria Rennotte passou a clinicar antes mesmo de revalidar o diploma, sendo, até onde se sabe, a primeira e única médica na capital paulista por mais de uma década. Conforme informa o Expositor Cristão de 17/2/1894, obteve "aceitação bem extensa (...) arranjando sempre maior clientela". No ano seguinte, apresentou na Faculdade de Medicina do Rio de Janeiro a tese para revalidação do diploma, conforme exigido por lei. ${ }^{15}$ Foi

America. Madison, The University of Wisconsin Press, 1997 e artigo da autora publicado neste dossiê, De "corpos" a "pessoas": a atuação das pacientes através do julgamento da Dra. Mary Dixon Jones de 1892.

${ }^{13}$ Alsop, History of the Woman's... Op. cit.

${ }^{14}$ Expositor Cristão, 17/2/1894.

${ }^{15}$ A tese tinha como título: Influência da Educação da Mulher sobre a Medicina Social. Rio de Janeiro, Tipografia Aldina, 1895. 
contratada como médica interna pela Maternidade de São Paulo, considerada a primeira instituição do gênero na cidade, voltada exclusivamente para assistência ao parto da mãe pobre.

Durante a sua gestão como diretora, preocupou-se com a situação financeira da entidade. Enviou então para diferentes jornais, pedidos de doações. ${ }^{16}$ Ela conseguiu tornar o estabelecimento conhecido, obteve doações, pagou os débitos feitos anteriormente, criou uma enfermaria cirúrgica e outra para atendimento de mulheres pobres não parturientes. ${ }^{17}$ Ao lado dessas atividades administrativas, exerceu a medicina, o que certamente lhe deu uma considerável experiência profissional em obstetrícia e ginecologia e maior segurança para exercer a clínica particular. Em junho de 1899, demitiu-se tendo, segundo sua avaliação, deixado a entidade com uma boa saúde financeira. ${ }^{18}$

Nos anos seguintes, Maria Rennotte dedicou-se à clínica, à pesquisa e à benemerência, integrou uma série de entidades de classe, culturais e filantrópicas, patrocinou diferentes projetos, ${ }^{19}$ realizou várias viagens e continuou usando jornais e revistas para expor suas idéias. Conquistou espaço e reconhecimento profissional, tornando-se uma figura conhecida, e até mesmo popular, em São Paulo.

A médica conquistou uma grande clientela, o que nos leva a pensar que, além da sua competência, existia não só um mercado para médicos estrangeiros voltados ao atendimento das

${ }^{16}$ Ver por exemplo anúncios no jornal O Estado de São Paulo publicados no ano 1896.

${ }^{17}$ RennotTe, M. The woman physician in Brazil. In: Woman's Medical College of Pennsylvania. Transactions of the Twenty-fifty Annual Meeting annual of the Alumnae Association of the Woman's Medical College of Pennsylvania. Philadelphia, Published by the Association, 1900.

${ }^{18}$ Atas da Diretoria. Maternidade de São Paulo, 1894-1899.

${ }^{19}$ Patrocinou projetos seus e de outras pessoas. Em 1896, subscreveu a lista de doações a Leolinda Daltro, que tinha como objetivo levar instrução aos índios de Goiás. CoRrÊA, Mariza. Antropólogas e Antropologia. São Paulo, Humanitas, 2003. 
Gênero, medicina e filantropia

comunidades imigrantes que se estabeleciam na cidade, de diferentes culturas, línguas e religiões, como existiam vozes favoráveis à prática da medicina por mulheres. A própria Maternidade de São Paulo, anos mais tarde, discutiu a contratação de uma outra médica que residisse na entidade. ${ }^{20}$ Vale destacar que se, na época, o exercício clínico por médicas tinha detratores que não viam nas mulheres qualidades para o exercício profissional, também tinha defensores, cujos argumentos baseavam-se em razões morais e na crença de que as mulheres tinham habilidades específicas, como a delicadeza e sensibilidade, o que as tornava melhores profissionais. ${ }^{21} \mathrm{~A}$ dificuldade em procurar um médico por parte do sexo feminino, em expor o próprio corpo, ou de suas filhas a um profissional masculino, somada à proibição de pais e maridos que os corpos de suas esposas e filhas fossem tocados por outro homem, faziam que muitas doentes ficassem sem tratamento, sendo, portanto, valorizado o serviço prestado pelas médicas. ${ }^{22}$

Num texto publicado por ocasião do encontro comemorativo de 25 anos do Woman's Medical College of Pennsylvania, Maria Rennotte refere-se aos problemas enfrentados $e$ às conquistas feitas ainda no início de carreira. Conta que embora as mulheres fossem consideradas seres muito inferiores no Brasil, durante um congresso seu nome foi lembrado para integrar a Comissão de Ginecologia e Obstetrícia e a Sociedade de Medicina e Cirurgia de São Paulo pediu que aceitasse. Quando fazia alguma comunicação nas reuniões da referida agremiação, os sócios a ouviam com atenção, assim também quando apresentou um instrumento de sua invenção, eles reconheceram o valor $e$ as vantagens na sua utilização. Diz:

${ }^{20}$ Atas da Diretoria. Maternidade de São Paulo, 18/10/1912.

${ }^{21}$ A Mulher e a Medicina. A Familia, 02/03/1889 e 09/03/1889.

22 SANCHEZ, R. M. Sympathy and Science... Op. cit.; MARQUES, Rita de Cássia. "É preciso ser piedoso": A imagem social do médico de senhoras. Belo Horizonte 1907-1939. Tese de doutorado, História, UFF, Niterói, 2003. 
Todo o corpo médico sempre me tratou com o respeito que eu desejaria. Certamente há exceções, como também têm nos Estados Unidos. No geral os brasileiros me tratam bem. Será que isso se deve ao fato deles saberem que anteriormente eu era educadora? Não sei. O importante é que aqui eu gozo de consideração e tenho uma boa clínica. $^{23}$

A médica informa também que possuía casa própria, na principal praça da cidade (Praça da Sé), e que planejava abrir dispensários para atendimento aos pobres em dois bairros de São Paulo onde se concentravam imigrantes italianos.

A "boa clínica" é atestada por outros documentos. Jorge Americano, no livro de memórias São Paulo naquele tempo, relembra que no final do século XIX e início do XX apenas os filhos de mães muito pobres nasciam na Maternidade de São Paulo, a maioria das crianças nascia em casa, as mães eram assistidas pela parteira Mme. Laborde, pela Dra. Maria Rennotte, e pelo Dr. Espinheira. ${ }^{24}$ Carlota Pereira de Queiroz, numa pequena autobiografia, menciona que quando tinha mais ou menos oito anos de idade foi com a mãe ao consultório de Maria Rennotte, a primeira mulher médica que conheceu. Afirma que ela tinha uma grande clientela, e foi então que a menina Carlota - que mais tarde se tornou médica - percebeu "que uma mulher podia exercer a medicina com sucesso". ${ }^{25}$

A grande clientela da médica pode ainda ser avaliada pelo retorno financeiro. Em 1914, ela era proprietária de pelo menos

\footnotetext{
${ }^{23}$ RennotTe, M. The woman physician in Brazil... Op. cit.

${ }^{24}$ Americano, J. São Paulo naquele tempo (1895-1915). São Paulo, Editora Saraiva, 1957, pp.482-3.

${ }^{25}$ Bernardes, M.T.C.C. Mulheres de ontem? São Paulo, T.A. Queiroz, 1989, pp.135-6.
} 
Gênero, medicina e filantropia

dois imóveis na cidade de São Paulo, na Rua Santo Antonio, 99 e 101 e na Rua Conselheiro Ramalho, 203. ${ }^{26}$

Pode-se dizer que Maria Rennotte conseguiu vencer algumas barreiras profissionais que muitas médicas, em outros países, apesar de lutarem com energia, não lograram alcançar no mesmo período: foi admitida como sócia de sociedade científica, trabalhou nos mais importantes hospitais da cidade e apresentou trabalhos em congressos médicos. Freqüentou, praticamente desde a fundação em 1895, a Sociedade de Medicina e Cirurgia em São Paulo. Assistiu às reuniões, integrou comissões, fez comunicações, deu sugestões e apartes que foram acatados, elogiados e também criticados. Por um certo período, atendeu no Hospital Samaritano, criado pela comunidade evangélica, mas devido a desentendimentos com a diretoria deixou de atuar naquele estabelecimento. ${ }^{27} \mathrm{Em} \mathrm{1906}$, a encontramos trabalhando na Clínica Cirúrgica da Enfermaria de Mulheres da Santa Casa de Misericórdia, ao lado de Arnaldo Vieira de Carvalho, um dos mais renomados médicos da época. Aí realizou operações durante as quais aplicava clorofórmio quente na anestesia para diminuir os efeitos colaterais - tema, aliás, de seu trabalho apresentado em 1910 para admissão como sócia titular da Sociedade de Medicina e Cirurgia de São Paulo. ${ }^{28} \mathrm{Na}$ década de 1910, viajou à Europa para visitar entidades filantrópicas, participou de Congressos Médicos (São Paulo, Rio de Janeiro e Belo Horizonte), quando apresentou trabalhos referentes à especialidade médica, como sobre outros temas que se dedicou com afinco: o da criação de uma filial da Cruz Vermelha em São Paulo e da necessidade de organizar na cidade uma melhor assistência à saúde da população mais pobre.

${ }^{26}$ Diário Oficial, 19/11/1914.

${ }^{27}$ Ata da Diretoria, 13/4/1905. Arquivo do Hospital Samaritano.

${ }^{28}$ Registro da Clínica Cirúrgica da Enfermaria de Mulheres (1905-1909). Museu da Santa Casa de Misericórdia; Rennotte, 1910. 
Finalmente a Cruz Vermelha foi fundada, em 1912, na cidade de São Paulo. No período da Primeira Grande Guerra a médica patrocinou inúmeras atividades. Em 1918, durante a epidemia de gripe espanhola, depois de se recuperar da doença, fechou temporariamente o consultório e, seguindo os preceitos da Cruz Vermelha de fornecer ajuda aos necessitados em caso de calamidade pública, foi socorrer as vítimas na cidade de Dois Córregos, interior do Estado. ${ }^{29}$ Aos 72 anos, em 1924, durante a revolta chefiada por Isidoro Dias Lopes, ela prestou serviços à população. ${ }^{30} \mathrm{Em} \mathrm{1926}$, dirigia juntamente com o médico Levinio de Souza e Silva um posto médico gratuito da Cruz Vermelha anexo à Escola de Enfermagem. ${ }^{31}$

Na década de 1920, a médica fez algumas viagens ao Rio de Janeiro. Em 1922, participou do Congresso Internacional de Proteção à Infância, organizado por Moncorvo Filho $e$ da recepção a Carrie Chapman Catt, organizada pela Federação Brasileira pelo Progresso Feminino. De volta a São Paulo, recepcionou a líder sufragista norte-americana e participou da fundação da Aliança Paulista pelo Sufrágio Feminino, da qual foi uma das vice-diretoras. ${ }^{32}$

No início dos anos 30, os jornais ainda noticiam a presença da médica em alguns eventos, como a palestra realizada sobre os direitos das mulheres em homenagem à presidente da Loja Teosófica de São Paulo; a assinatura de manifesto pró General Isidoro Dias Lopes; a participação em reuniões do Instituto Histórico e Geográfico, do qual foi sócia por quatro décadas; a doação feita à Casa Maternal criada pela Cruzada Pró-Infância,

\footnotetext{
${ }^{29}$ A Capital, 11/11/1918.

30 O Estado de São Paulo, 21/7/1924. DE LuCCA, E. e DE LuCCA, J.B.A. Marie Rennotte, pedagoga e médica. Subsídios para um estudo histórico-biográfico e médico-social. História, Ciência, Saúde-Manguinhos, vol. 10, n 2, maio-ago 2003, pp.703-725.

${ }^{31}$ O Estado de São Paulo, 1/12/1926.

${ }^{32}$ NAZÁRIO, D.N. Voto feminino e feminismo. São Paulo, scp, 1923.
} 
Gênero, medicina e filantropia

entre outros objetos, de uma mesa cirúrgica - que sugere que estivesse se desfazendo do consultório. ${ }^{33}$ Depois de uma homenagem feita pela Cruz Vermelha, em 1935, as notícias são as mais tristes possíveis. ${ }^{34}$ Estava cega, surda, doente e pobre. O governo estadual, em 19/1/1938, reconhecendo os relevantes serviços lhe deu uma pensão. Morreu aos 90 anos, em novembro de 1942, tendo vivido mais de 60 anos no Brasil.

\section{Papel social das mulheres}

Os escritos publicados no Brasil por Maria Rennotte, abrangem um período de 40 anos. Os primeiros artigos localizados até o momento, na Gazeta de Piracicaba, datam de 1882, e o último, de 1925, publicado nos Anais do Primeiro Congresso de Proteção à Infância, organizado por Moncorvo Filho. Podem ser divididos em quatro temas: educação; condição das mulheres; beneficência; e prática médica. Apontam para as múltiplas influências, destacando-se o iluminismo, o positivismo e o lamarckismo. Entre os autores citados, encontram-se filósofos, educadores, literatos, poetas, políticos, médicos, cientistas, tais como Montesquieu, Voltaire, Balzac, Victor Hugo, Danton, Bismarck, Marie France, Margueritte de Valois, Alfred de Musset, Pestalozzi, Jules Simon, Emerson, James Mill, Paré, Claude Bernard. Os textos evidenciam, ainda, o gosto da biografada por notícias da atualidade, o que sugere ter sido uma leitora atenta de jornais, e o desprezo pela literatura de evasão como os folhetins.

A preocupação com a condição das mulheres esteve presente ao longo da vida de Maria Rennotte, porém os textos encontrados sobre o tema referem-se sobretudo ao final do século XIX e início do XX. Das conferências, palestras e comunicações feitas nas décadas de 20 e 30, foi localizada apenas a proferida no

33 O Estado de São Paulo, 2/10/1930, 12/6/1931 e 16/8/1932.

${ }^{34}$ ID., 22/11/1942. 
Congresso de Proteção à Infância, as demais não sabemos se foram publicadas. ${ }^{35}$

Tendo iniciado suas atividades no país em pleno regime escravista, a educadora reproduz em vários de seus artigos a imagem de família brasileira encontrada em muitas obras do século XIX, nas quais as mulheres viviam sob forte opressão masculina, numa condição aviltante semelhante à escravidão. No Brasil, diz, os dois sexos estavam constituídos em duas categorias, totalmente distintas e separadas. "Uma composta por indivíduos altivos, nobres, sólidos, independentes, corajosos, instruídos" que sozinhos se viam na obrigação de lutar pela vida. Do outro lado, o sexo feminino, desterrado para dentro da casa, "máquina de reprodução" tratado abaixo de sua dignidade, "como um ser que nada pode, para não dizer completamente nulo". ${ }^{36}$ "Raça dos parasitas, caracterizada por hábitos de obediência e sujeição, por sua indolência, fraqueza, servilismo e ignorância." 37

A culpa dessa "injustiça inveterada" devia-se ao homem. Foi ele quem trabalhou para o enfraquecimento e diminuição das faculdades mentais do sexo feminino, retendo a mulher na ignorância, presa ao lar, "no intuito de fazer dela uma criada ou um instrumento de seus prazeres, e seus caprichos". Num artigo publicado no jornal $A$ Familia, afirma que a organização física da mulher permitiria, se educada como o homem, a ter a mesma resistência, força, inteligência. "A Providência os criou ambos, e os fisiologistas de nossos dias, reconhece-lhe (à mulher) tantas aptidões como ao homem". Ambos possuem razão, imaginação, memória e vontade. Se a mulher apresentava falta de lógica e de

${ }^{35}$ RenNOTTE, M. A eficiência das escolas na manutenção dos hospitais infantis. Anais Primeiro Congresso de Proteção à Infância. Rio de Janeiro, Imprensa Nacional, 1925, pp.500-504.

${ }^{36}$ ID. A Educação da Mulher. Gazeta de Piracicaba, 30/8/1882.

${ }^{37}$ ID. A luta pela existência e a necessidade de associação para a luta. A Familia, 4/5/1889. 
Gênero, medicina e filantropia

raciocínio e se mostrava ignorante, isto se devia à educação que recebia, não ao tamanho do cérebro. ${ }^{38}$

Imbuída da visão burguesa do casamento romântico, que valoriza o companheirismo e o papel da mulher como esposa $e$ mãe de família, Maria Rennotte denuncia as conseqüências funestas resultantes do autoritarismo masculino e da situação de privação de liberdade em que era mantido o sexo feminino, obrigado a obedecer, sem instrução, ocioso e em estado de "paralisia cerebral". O homem não tinha uma companheira com quem pudesse contar em caso de necessidade ou com quem compartilhar os prazeres intelectuais, eram "duas pessoas estranhas, incompreensíveis, uma para a outra"; o filho não tinha uma mãe que lhe abrisse os "segredos da natureza", pois ela mesma não possui a chave do conhecimento; ${ }^{39}$ e a nação também não podia contar com ela, pois assistia "plácida e sossegada, as crises e alterações, as perturbações sociais, sem sentir-lhe o sangue correr nas veias". ${ }^{40}$

Defende a idéia de que as características obtidas ao longo da vida são transmitidas para outras gerações e que a educação da mulher era fundamental para a civilização e desenvolvimento da espécie. ${ }^{41}$ Afirma que assim como a influência da mulher pode enriquecer a choupana e civilizar os povos, também poderia levar qualquer país à decadência. No Brasil, alerta, apenas $7 \%$ da população feminina sabia ler. Pela falta de educação, a mulher vinha procriando filhos pouco inteligentes, débeis, inclinados ao servilismo. Critica em tom eloqüente quem considera a atividade de educar um filho de dar-lhe não só "o leite do corpo como o do espírito", como sendo menor. ${ }^{42}$

\footnotetext{
${ }^{38}$ ID. Mulher e a Liberdade. A Familia, 23/5/1889.

${ }^{39}$ ID. A Educação da Mulher. Op. cit.

${ }^{40}$ ID. Mulher e a Liberdade. Op. cit.

${ }^{41}$ ID. A luta pela existência e a necessidade de associação para a luta. A Familia, 4/5/1889; e Influência da Educação... Op. cit.

${ }^{42}$ ID. A luta pela existência... Op.cit. e Influência da Educação... Op. cit.
} 
Os riscos de "caducidade" do país eram, portanto, muito grandes. Para a evolução da própria espécie e o progresso da nação, para acabar com a ignorância, debilidade, vício, miséria $e$ tirania não era necessária a revolta, mas que o homem tirasse o sexo feminino da letargia que se encontrava e reconhecesse seu valor e capacidade.

Considera a educação dada ao sexo feminino fútil, superficial, sem atrativos, massacrante, cheia de sentimentalismo $e$ supersticiosa, na qual a aquisição dos ditos predicados acabava por resultar em frivolidade, desgaste físico, excessos e excitação nervosa. Denuncia que a educação não preparava as moças para a vida, seja para o papel de esposa ou mãe de família, seja para enfrentar as dificuldades advindas de situações adversas como orfandade ou viuvez, nem para a aquisição de uma profissão. Considera a educação também insuficiente e insatisfatória do ponto de vista físico. Lembra que o desenvolvimento intelectual não é possível sem o desenvolvimento físico. Desconhecendo o funcionamento do próprio organismo, desde a mais tenra idade, a mulher colocava em risco a saúde. Que energia, que pensamentos, que descendência poderia ter um corpo debilitado pelas exigências absurdas da moda e dos costumes, que preconizam o uso de roupas inadequadas, perguntava. Como suas colegas do Woman's Medical College of Pennsylvania denunciava o uso do espartilho pelas conseqüências funestas que acarretava para a saúde, causando inúmeras doenças e restringindo o esforço físico saudável e prazeroso, como aquele obtido pela ginástica. ${ }^{43}$

Num artigo publicado no jornal $A$ Família, intitulado "Mulher e Liberdade", às vésperas da mudança para a Filadélfia, é possível entender a relação que estabelece entre a mãe educada, o papel social das mulheres e a cidadania. Para ela, a liberdade podia ser definida como "a condição do ser que não pertence a senhor algum". Pode também ser definida como livre arbítrio. Porém não significa o direito ao ócio, à despreocupação. "A

${ }^{43}$ ID., IB. 
Gênero, medicina e filantropia

liberdade pode compreender a faculdade de fazer uma coisa de preferência a outra, mas nunca pode significar negação da ação". Todo ser humano tem a obrigação de ser útil para "o bem da grande família humana". A ação traz consigo a noção de responsabilidade e a mulher que faz parte da humanidade assume responsabilidades iguais ao homem perante a sociedade. Se ela tem responsabilidades, ela deve gozar dos mesmos direitos que este. ${ }^{44}$

Portanto, é a partir do exercício dos seus deveres que a mulher tem direito à cidadania. Ela não pode gozar, nem exigir seus direitos, se não partilhar dos deveres. Deve, pois, cumprir suas responsabilidades em relação à pátria, seja educando os filhos de forma conveniente, seja realizando trabalhos para a coletividade, como por exemplo, a ação social voluntária. Pela prestação de serviços à nação, a mulher daria provas de sua afeição ao solo natal e poderia reivindicar o título de filha de um país. Maria Rennotte ressalta que os préstimos da mulher para a pátria eram diferentes daqueles prestados pelos homens. Não se tratava de exigir que o sexo feminino seguisse na frente dos campos de batalha na defesa do Estado. No tempo de guerra, sua missão deveria ser ministrar os primeiros socorros aos feridos. Quando ocorressem calamidades, levar alívio aos necessitados. Deveria ainda suprir as carências na área médica e social e promover a prevenção aos menos favorecidos. ${ }^{45}$

A médica via a benemerência como um dever social de homens e de mulheres; um valor moral a ser ensinado às crianças. ${ }^{46} \mathrm{~A}$ ação social era concebida como institucionalizada, científica e de qualidade (daí a organização de campanhas para levantamento de fundos e cursos para formação de voluntárias), voltada para aqueles considerados realmente necessitados, com

\footnotetext{
${ }^{44}$ ID. Mulher e a Liberdade. Op. cit.

${ }^{45}$ ID. Apelo às paulistas. O Estado de São Paulo, 10/2/1894.

${ }^{46}$ ID. A eficiência das escolas... Op. cit.
} 
vistas ao bem estar total dos indivíduos, à promoção social dos assistidos e ao progresso nacional.

\section{Ação Social}

Com esses argumentos, Maria Rennotte conclamou as mulheres, no Brasil, a fazerem a sua parte pelo país. Desde 1893 defendeu na imprensa a idéia de criar a Cruz Vermelha (CV) em São Paulo e de treinar enfermeiras voluntárias para prestar "socorro inteligente" em tempo de guerra e calamidades. ${ }^{47} \mathrm{Em}$ 1894, publicou em $O$ Estado de São Paulo um artigo "Apelo às Paulistas" tratando do assunto. A visita que fez à Exposição Universal em Paris, em 1889, durante a qual percorreu as instalações da CV deve ter lhe causado, forte impressão. ${ }^{48}$

A idéia de criação da $\mathrm{CV}$, porém, não frutificou de imediato, demorando mais de 10 anos para ser implementada. No final do século XIX, a organização e participação de mulheres em associações voluntárias leigas (femininas e mistas) ainda era bastante rara. A partir do início do século $\mathrm{XX}$, com o desenvolvimento urbano $e$ industrial, a ampliação das oportunidades educacionais para as mulheres das camadas médias e de elite e a crescente demanda de movimentos sociais, esta situação se modificou rapidamente.

A médica foi comissionada pela Sociedade de Medicina e Cirurgia de São Paulo para fazer uma viagem à Europa, com o objetivo de observar a CV em alguns países e colher informações

\footnotetext{
${ }^{47}$ A Cruz Vermelha Internacional foi criada em 1863, em Genebra, na Suíça, pelo empenho de Henri Dunant, com o objetivo de providenciar socorro não partidário para feridos de guerra. Posteriormente o programa da sociedade foi ampliado, incluindo a organização de serviços gratuitos de saúde, como hospitais postos de saúde, a ajuda a vítimas de desastres e calamidades públicas, a assistência aos prisioneiros de guerra e a fundação de cursos para formação de enfermeiras voluntárias e profissionais.

48 O Estado de São Paulo, 10/2/1894.
} 
Gênero, medicina e filantropia

para a organização de uma filial em São Paulo, abraçando a partir de então com mais força a causa da fundação. ${ }^{49}$

A CV de São Paulo foi oficializada em outubro e o jornal Correio Paulistano de 6/10/1912 noticiou a solenidade de inauguração. ${ }^{50}$ Pela relação dos participantes, verifica-se que a associação recebeu apoio do governo do estado e da elite paulistana, Maria Rennotte assumiu o cargo de presidente efetiva da sociedade, cabendo a presidência honorária a Rodrigues Alves e Paulina de Souza Queiroz, e teve desde a fundação intensa participação feminina.

Segundo informa a médica, inicialmente, a entidade não recebeu grande apoio da população devido à suposição que sua função era prestar auxílio ao governo apenas em tempo de guerra $e$ "sendo o Brasil, uma nação essencialmente pacífica (...) não tinha aqui razão de existir entre nós". Assim que ficou demonstrado pelos atos, que a CV também se ocupava de "outras questões de utilidade pública; que estuda(va) problemas que se relaciona(va)m com o bem estar do povo" passou a receber "numerosissimas adesões". 51

Desde o início da CV em São Paulo, as ações sociais tiveram por objetivo suprir carências na área da assistência à saúde $e$ a profissionalização das mulheres destacando-se entre elas a criação da escola de enfermeiras e a fundação de um hospital infantil.

\section{A escola de enfermagem}

A defesa da necessidade de formação específica para pessoal de enfermagem era uma questão nova do século XIX até

\footnotetext{
${ }^{49}$ RenNotTe, M. Relatório da Dra. Rennotte sobre a "Cruz Vermelha". Arquivo da Sociedade de Medicina e Cirurgia de São Paulo, vol. 2, n 7, jun. 1911, pp.237-251

${ }^{50}$ Cruz Vermelha. Histórico da Cruz Vermelha Brasileira. 1908-1923. Primeira Conferência pan-americana da Cruz Vermelha. Rio de Janeiro, scp, 1923.

51 O Estado de São Paulo, 5/1/1913.
} 
mesmo para os médicos. ${ }^{52} \mathrm{O}$ antigo pessoal composto, em geral, por religiosas e enfermeiros/as práticos/as, não satisfazia mais às novas exigências da profissão, das ciências médicas $e$ das transformações que vinham ocorrendo nos hospitais. Em 1890, foi criada no Asilo dos Alienados, no Rio de Janeiro, aquela que é considerada a primeira escola de enfermagem do Brasil, hoje denominada Alfredo Pinto. ${ }^{53}$ Em São Paulo, para suprir essa carência foram inicialmente contratadas enfermeiras diplomadas estrangeiras e depois criadas algumas escolas, destacando-se entre elas a do Hospital Samaritano, as da Cruz Vermelha e da Santa Casa de Misericórdia. ${ }^{54}$

Maria Rennotte defendia dois tipos de ensino de enfermagem: o voluntário e o profissional. Nas primeiras décadas do século $\mathrm{XX}$, ela teria organizado um "curso de enfermagem profissionalizante", que funcionou na Associação Feminina Beneficente.$^{55}$ Essa entidade filantrópica voltada para a assistência à infância e à educação das mulheres, criada por Anália Franco, teve apoio e colaboração de Maria Rennotte não só na organização do curso, como também na prestação de serviços médicos e participação no conselho diretor. ${ }^{56}$

Quanto ao curso de enfermeiras voluntárias, tinha entre os objetivos formar pessoal qualificado, fazendo que em todos os meios sociais penetrassem noções corretas de higiene $e$ dos

\footnotetext{
${ }^{52}$ Algumas médicas em diferentes países patrocinaram cursos de enfermagem, destacando-se entre elas Anna Hamilton, na França e Cecilia Grieson, na Argentina.

${ }^{53}$ Moreira, A. Profissionalização da Enfermagem Brasileira. O pioneirismo da Escola de Enfermagem Alfredo Pinto. Tese de Doutorado, Escola de Enfermagem da USP, 2003.

${ }^{54}$ MotT, M.L. Revendo a História da Enfermagem em São Paulo (1890-1920), Cadernos Pagu (13), Núcleo de Estudos de Gênero-Pagu/Unicamp, 1999, pp.327-355,

${ }^{55}$ Montelro, E. C. Anália Franco. A grande dama da Educação Brasileira. São Paulo, Editora Eldorado Espírita de São Paulo, 1992.

${ }^{56}$ O Estado de São Paulo, 14/9/1919.
} 
Gênero, medicina e filantropia

cuidados aos doentes, "desfazendo os erros e preconceitos arraigados no povo". Além disso, serviria para substituir "as distrações fúteis pelo gosto do estudo e pelas ocupações proveitosas", elevando conseqüentemente "o nível moral feminino". ${ }^{57}$

A escola de enfermeiras, fundada em 1912 na cidade de São Paulo, é considerada a primeira instituição de ensino da CV criada no Brasil. Em 1917, a Revista Feminina noticiou o compromisso de honra das alunas ocorrido no mês de junho. Pelos artigos, verifica-se que havia dois tipos de cursos, um de socorros urgentes e um de enfermeiras profissionais, que tinham como professoras Maria Rennotte e a médica portuguesa Casemira Loureira. Na relação de nomes das formandas, encontra-se entre outros o da pintora Anita Krug Malfatti, cuja exposição causou polêmica nesse mesmo ano, na cidade. ${ }^{58}$

Depois do final da Grande Guerra, o curso teria entrado em um período de refluxo, voltando a funcionar de forma intermitente até 1940 , passando inclusive a aceitar alunos do sexo masculino. ${ }^{59}$ A importância da criação da escola, conforme já mencionei em outro texto, merece ser analisada com cuidado e sugere um significado maior do que em geral the é atribuído pela historiografia brasileira. ${ }^{60}$ Primeiro, por contribuir para o suprimento de mão de obra especializada, tão necessária na época sobretudo pela expansão dos serviços de saúde na cidade. Segundo, por fazer recuar o marco do início da profissionalização da enfermagem no Brasil. Até bem recentemente a Escola de Enfermeiras Dona Anna Nery (1923), fundada no Rio de Janeiro e

${ }^{57}$ RenNotte, M. Um apelo às senhoras brasileiras. Anais do VII Congresso Brasileiro de Medicina e Cirurgia, Belo Horizonte, 1912, pp.122-131.

${ }^{58}$ Cruz VermelHA. Revista Feminina 4(38), julho 1917.

${ }^{59}$ O Estado de São Paulo, 31/1/1919.

${ }^{60}$ Mott, M. L e TsunEChiro, M. A. Os Cursos de Enfermagem da Cruz Vermelha Brasileira e o início da Enfermagem Profissional no Brasil. REBEN(5), setembrooutubro 2002, pp.592-599. 
a Associação de Enfermeiras (1926) eram consideradas marcos fundadores da enfermagem profissional no Brasil. A CV de São Paulo não só patrocinou o ensino da enfermagem quase uma década antes, como organizou aquela que talvez seja a primeira associação de enfermeiros do Brasil. Em 7/10/1918, O Estado de São Paulo noticiou a realização, na sede da entidade, de uma reunião de enfermeiras práticas e diplomadas e a eleição da primeira diretoria "de uma sociedade para a defesa dos interesses da classe". Maria Rennotte esteve presente nessa reunião e foi escolhida como presidente honorária.

\section{Casa para convalescentes}

No mesmo ano da fundação da Cruz Vermelha em São Paulo (1912), a médica lançou duas outras campanhas de assistência médica e social privada - uma em favor da fundação da casa para convalescentes, e a outra para a criação de um hospital de crianças. Ambas com vistas a promover a saúde da população e diminuir as taxas de mortalidade, pelo valor material que o trabalhador representava para a nação. Podem também ser lidas como projetos de intervenção médica na sociedade e reflexo da imagem social que estes profissionais passam a se atribuir, a de responsáveis pelo destino da nação por depender deles a saúde da população.

A primeira campanha não foi adiante, pareceu impossível de ser realizada por alguns médicos da Sociedade de Medicina $e$ Cirurgia de São Paulo. Apoiando-se na idéia que toda energia humana não utilizada (incapacitados, desocupados) representava um peso morto para o progresso e a riqueza da nação, Maria Rennotte propôs a abertura de uma enfermaria fora da cidade, uma espécie de 'colônia' agrícola, tipo de instituição bastante em voga na época, destinada a recuperar os indivíduos pelo trabalho $e$ vida ao ar livre. ${ }^{61}$ Esses estabelecimentos, segundo a médica,

${ }^{61}$ Rennotte, M. Cruz Vermelha. Arquivo da Sociedade de Medicina e Cirurgia (3) 3-8, mar./ago. 1912, pp.111-2. 
Gênero, medicina e filantropia

deveriam receber e consolidar a cura de convalescentes pobres sem condições de realizar trabalho pesado, onde além de condições higiênicas ideais, os assistidos desempenhariam atividades segundo suas forças. Justifica a proposta devido ao pequeno número de hospitais, nos quais os leitos não cresciam na mesma proporção que a população, e à impossibilidade da Santa Casa em atender a todos que ali afluíam.

As idéias de Maria Rennotte apontam para uma concepção moderna de hospital. Considera como um lugar de tratamento $e$ cura, não mais de asilo, e como local de ensino e treinamento clínico para profissionais de saúde. Para ela, os convalescentes deveriam ficar fora dos hospitais, pois obstruíam as enfermarias, tinham o restabelecimento mais lento por respirarem o ar viciado, presenciarem o sofrimento alheio e pesavam nas despesas "de um estabelecimento criado unicamente para curar" ${ }^{62}$

Quanto ao ensino clínico, os lugares para a prática médica eram limitados, se restringiam, no período, a alguns hospitais $e$ enfermarias em sua maioria particulares (filantrópicos). Diz Maria Rennotte que além de ajudar os necessitados, esses estabelecimentos permitiriam aos estudantes adquirir conhecimentos e aos mestres aplicar e estender "as suas capacidades e talentos" ${ }^{63}$ Esse tipo de pensamento, diria, "utilitário" da filantropia, visando o ensino clínico, não era exclusivo da médica, ao contrário teria norteado, segundo alguns autores, a criação de hospitais e policlínicas privados a partir do final do século XIX. ${ }^{64}$

As idéias da médica apontam ainda para a preocupação com a higienização e organização do espaço urbano $e$ a

${ }^{62}$ Os grifos são de Maria Rennotte.

${ }^{63}$ Rennotte, M. Os estabelecimentos de Beneficência com a Medicina Social. Anais do Primeiro Congresso Médico Paulista. São Paulo, Seção de Obras d'O Estado de São Paulo, 1917, pp.211-6.

${ }^{64}$ GadelHA, P. Assistência Médica no Rio de Janeiro (1920-1937). Reformas Institucionais e na prática médica. Dissertação de Mestrado, Instituto de Medicina Legal, UFRJ, 1982. 
eliminação, ou pelo menos o controle, das desordens de cunho social. As casas para convalescentes ao mesmo tempo em que promoveriam a recuperação da saúde, prestariam um outro serviço: contribuiriam para que os fracos se recuperassem mais rapidamente, possibilitaria o desenvolvimento do hábito de trabalho, evitando a mendicidade, livrando assim as ruas do mendigo, do ladrão, do vagabundo e do bêbado, que ofereciam um espetáculo que não condizia "com o grau do nosso adiantamento." 65

\section{Hospital para crianças}

No que diz respeito à criação do primeiro hospital infantil da cidade de São Paulo, a proposta se baseava na crescente preocupação de médicos, educadores, políticos e filantropos com a mortalidade infantil. A defesa da criação de hospitais específicos para crianças era nova na época e desenvolveu-se em paralelo à Pediatria, que no Brasil data do final do século XIX.

Analisando a situação da assistência às crianças pobres enfermas em São Paulo, Maria Rennotte ressalta a precariedade de meios existentes. A saúde pública na época era voltada, sobretudo, para o combate de epidemias, havendo um reduzido número de hospitais mantidos pelo governo. A assistência médica era patrocinada basicamente por entidades privadas. $\mathrm{Na}$ cidade, havia uma única enfermaria para crianças na Santa Casa com 40 leitos. Segundo a médica, a mortalidade infantil por semana era de 130 a 140 indivíduos, o que significava que nem um terço dos doentes poderiam ser socorridos. Explica que dessa enfermaria eram excluídas as crianças maiores de 10 anos que iam para a enfermaria de adultos, deixando evidente a visão que possuía da infância como etapa da vida caracterizada por uma natureza moral específica, um ser em formação, passível de ser moldado: "imagine-se o horror dessa promiscuidade, em que alminhas

${ }^{65}$ RenNotTe, M. Cruz Vermelha. Op.cit. 
Gênero, medicina e filantropia

puras, colocadas ao lado de indivíduos por ventura perversos, e, mal grado toda a vigilância, terão de ouvir colóquios talvez horríveis, a lhes envenenarem o coração para o resto dos seus dias." 66

A preocupação da médica com a mortalidade infantil sugere ao mesmo tempo uma atitude humanitária, demonstrada pela preocupação com a precariedade da assistência médica sofrida pela população mais pobre, como também uma percepção do valor da criança como capital humano, valioso patrimônio a ser preservado. Para a médica a criança representava o futuro, a força, o progresso da nação. Representava também a defesa dos direitos e da integridade da pátria. Nesse sentido, o dinheiro gasto com a imigração deveria ser destinado à saúde da população nacional, evitando-se assim os riscos de problemas futuros com o elemento estrangeiro.

A idéia da fundação do hospital recebeu apoio da sociedade em geral e acabou resultando na fundação, em 1918, do Hospital de Crianças de Indianópolis, bairro então distante do centro e pouco povoado, onde Anésia Pinheiro Machado faria, alguns anos mais tarde, suas primeiras experiências com a aviação. Para a realização do projeto, Maria Rennotte procurou mobilizar toda a sociedade, não apenas as classes médias e as elites, mas também os trabalhadores, as crianças, em particular, os escolares. ${ }^{67}$

Para concluir gostaria de destacar que Maria Rennotte, com seus escritos e prática social, denunciou a desigualdade entre os gêneros, lutou pelo direito das mulheres enquanto indivíduos a uma melhor educação, ao acesso a diferentes tipos de trabalhos, à obtenção de um corpo mais saudável, à cidadania política. O

\footnotetext{
${ }^{66}$ ID., IB.

67 O Estado de São Paulo, 5/1/1913.
} 
empoderamento das mulheres pela maternidade, defendido por muitas feministas no período, não foi sua tônica.

A análise de sua trajetória traz elementos importantes para a discussão do significado da participação feminina nas entidades assistenciais. Possibilita repensar o papel que essas associações tiveram na transformação da consciência das mulheres $e$ na organização do movimento feminista brasileiro, por favorecer a circulação de idéias e de questionamentos novos, o convívio com outras mulheres, a administração de problemas fora do grupo familiar e o estabelecimento de redes de interesse. Possibilita inclusive afirmar que pela atuação nas associações as mulheres participaram da vida nacional, apesar de não terem reconhecido os direitos políticos. Pela criação, planejamento e administração das entidades deixaram sua marca na vida pública na virada do século XIX para o XX: seja nos serviços prestados à população mais pobre, num período que havia uma falta crônica de locais para atendimento médico; bem como nas leis, na organização de instituições de ensino e na construção do conhecimento científico. Contribuíram de forma efetiva nos projetos de reconstrução da nação elaborados após a proclamação da República, vale ressaltar, apesar de lhes serem negados os direitos políticos. 